\title{
Special Interest Group for Neuroscience in Psychiatry
}

\author{
Guy M. Goodwin
}

The inaugural meeting of a Special Interest Group for Neuroscience in Psychiatry was held at the meeting of the College in Glasgow in 1995 , chaired by Professor Stuart Checkley.

The following statement has been prepared for the group to announce its existence and stimulate discussion of its aims.

The mission of the group will be to promote the application of neuroscience to the core problems of aetiology and treatment in psychiatry. The term neuroscience encapsulates those aspects of anatomy, physiology. pharmacology, genetics and psychology which contribute mutually to an improved understanding of how the brain functions in health and disease.

Neuroscience is an emergent discipline which lies naturally at the heart of reliable knowledge in many aspects of general psychiatry. It is a preclinical development with origins in shared problems in neuroanatomy, neurophysiology. neuropharmacology, genetics and psychology. It is necessarily a multidisciplinary enterprise and it takes as its central questions how the brain works and how it goes wrong in disease. It is unlike the traditional subject groups in basic medical science by having as its focus the brain. not a set of related techniques.

There are important parallels between basic neuroscience and the multidisciplinary structure of medicine itself which will be recognisable to clinicians. However, neuroscience has its own tensions. The creation of a whole unified from historically separate techniques or strands of scholarship is difficult. The priorities within neuroscience are fluid and the creation of courses or departments often follows existing strengths in traditional subjects like physiology or pharmacology. We should be prepared to argue that psychiatry poses neuroscience's most challenging applied problems. Furthermore, the support of basic research will increasingly have to be justified by its relevance to the discovery of treatments for mental illness, ageing, dementia and the failures of brain development that result in learning disability. There will be a continuing need for clinicians to understand and influence the development of neuroscience so that it meets needs as well as satisfying curiosity.

However, there are lessons from the success of neuroscience that psychiatry, in particular, may need to learn. The meetings of the Brain Research Association and the British Association for Psychopharmacology in this country, and particularly the Society for Neuroscience in the USA are exciting events. There is a palpable sense that scientists originally from competing disciplines have agreed to sink their differences to evolve a common view of brain function or cognition. Traditional distinctions between what is biological and what is psychological are met, at times, with refreshing disbelief. This effort to overcome competing, tangential formulations of a given problem has important implications for psychiatry. How long can we go on attempting to accommodate blology, psychoanalysis, anthropology, social science, learning theory and cognitive psychology as equally contributing views of mental illness without any effort at synthesis or pruning?

To promote neuroscience in psychiatry will demand an increasing understanding of the methods and language of the basic scientists who are shaping its development. This has implications for the content of both postgraduate training and for continuing professional development in general psychiatry. At present, while the syllabus of the MRCPsych course places an appropriate emphasis upon neuroscience, the content of the examination appears to lag behind. This is an area where the interest group would hope to make a direct impact.

Our current understanding of how the brain works is highly provisional and demands a due humility. However, support of neuroscience in psychiatry will imply a stand against nonscientific discourse. In particular, the claims for some anthropological, psychosocial or postmodern philosophical 'explanations' in psychiatry appear to reject hypothesis testing as it is commonly understood within the natural sciences. Such approaches are likely only to bring discredit to the intellectual standing of psychiatry and further confuse its practice. 
It is proposed that the term biological psychiatry should not be used as the name for the new section for two reasons. The most important is the implication that we are contributing a narrow view of psychiatry based on a restricted set of data. More trivially it is sometimes inferred that biological psychiatrists take an impersonal view of their patients because of their commitment to objective rather than subjective phenomena.

We have previously seen a special interest group for biological psychiatry elect to disband and be subsumed within the general psychiatry section. This perhaps reflected the logic of the view subsequently articulated by Guze when he posed the question, "Biological psychiatry, is there any other kind?". However, the disappearance of the biological psychiatry interest group has not seen a transfusion of energy into general psychiatry. Instead, the 1994 Trainees' Forum seems to have concluded that there has been a disappointing decline in its fortunes and that training in general psychiatry is in crisis (Gaughran \& Davies, 1995). The new interest group does not have the redefinition of general psychiatry as its objectve, although general psychiatry's problems are likely to remain of vital professional concern to many of the members of the neuroscience interest group. However, to support the academic strength of psychiatry when the growth of neuroscience and its achievements are so exciting is likely to increase the morale and purpose of psychiatrists generally. By these means and by the direct improvement of evidence based treatments, support of the neuroscience interest group will also be to the advantage of our patients.

\section{Reference}

Gaughran, F. \& Davies, S. (1995) 1994 Trainees' Forum: 'Is general psychiatry dead?' Psychiatric Bulletin, 19. 121-122.

Guy M. Goodwin, Professor of Psychiatry and Honorary Consultant, University Department of Psychiatry and MRC Brain Metabolism Unit, Royal Edinburgh Hospital, Morningside Park, Edinburgh EH10 5HF

\section{Psychiatric Aspects of Physical Disease}

\section{Edited by Allan House, Richard Mayou \& Christopher Mallinson}

This book describes the extent and nature of psychiatric problems associated with physical illness and the ways in which both can be managed by physicians and psychiatrists. Examples are given of simple measures that can be incorporated into routine care and of occasions where specialist referral is appropriate. The book comprises edited papers based on a joint conference of the Royal Colleges of Physicians and Psychiatrists together with additional editorial sections. It provides a sister volume to Medical Symptoms not Explained by Organic Disease and complements the joint report of the two Colleges on Psychological Care of Medical Patients: Recognition of Need and Service Provision.

\section{$\bullet £ 15.00 \bullet 110$ pp. $・ 1995 \bullet$ ISBN 1873240929}

Available from bookshops and from the Publications

Department, Royal College of Psychiatrists, 17 Belgrave Square, London SW1X 8PG (Tel. 0171-235 2351, extension 146) 